\title{
Drinking water ivermectin treatment for eradication of pinworm infections from laboratory rat colonies
}

\author{
A. LYTVYNETS ${ }^{* 1,2}$, I. LANGROVÁ ${ }^{2}$, J. LACHOUT ${ }^{1}$, J. VADLEJCH ${ }^{2}$, A. FUČÍKOVÁ ${ }^{3}$, I. JANKOVSKÁ ${ }^{2}$
}

${ }^{1}$ Department of Laboratory Animal Breeding and Hygiene, Institute of Physiology, Academy of Sciences of the Czech Republic, Videnska 1083, 14220 Prague 4-Krc, Czech Republic, "E-mail: litvinec@biomed.cas.cz; ${ }^{2}$ Department of Zoology and Fisheries, Faculty of Agrobiology, Food and Natural Resources, Czech University of Life Sciences in Prague, Kamycka 129, 16521 Prague 6-Suchdol, Czech Republic; ${ }^{3}$ Department of Veterinary Sciences, Faculty of Agrobiology, Food and Natural Resources, Czech University of Life Sciences in Prague, Kamycka 129, 16521 Prague 6-Suchdol, Czech Republic

\begin{abstract}
Summary
The effects of ivermectin were studied in laboratory rats naturally infected with the pinworm Syphacia muris. Ivermectin was administered over four 5-days periods in drinking water; the ivermectin dose was $2.5 \mathrm{mg} / \mathrm{kg}$ of body weight per day. All the rats were weighed every five days and their ova production was monitored by a cellophane tape test. Every fifth day six males and six females from the experimental group were euthanized and examined for adult pinworms and larvae. The rats' health condition, behaviour and consumption of food and water were monitored every day. The aim of this study was to investigate the effectiveness of orally administered ivermectin as a treatment against adult pinworms and their larvae in laboratory rat colonies.
\end{abstract}

Keywords: Syphacia muris; Aspiculuris tetraptera; ivermectin; laboratory rat; pinworm

\section{Introduction}

Laboratory animals, especially laboratory rodents, are necessary for biomedical research. Therefore, the quality and reliability of laboratory animals have a major influence on research. That is the reason why animals, which are standardized as much as possible, are important prerequisites for reproducible animal experiments. Only healthy, well provided for animals yield valid scientific data and thus obliges us to the highest standards of care.

Oxyurids (Syphacia muris and Aspiculuris tetraptera) are common contaminants in most laboratory rat colonies (Habermann \& Williams, 1958; Stahl, 1961; Flynn, 1973). The male of $S$. muris is $1.2-1.3 \mathrm{~mm}$ long. The tail is thin and about twice as long as the body width. A single, slender long spicule and gubernaculum are present. The female is $2.8-4.0 \mathrm{~mm}$ long with the vulva located in the anterior quarter of the body (Flynn, 1973; Lewis \& D'Silva, 1986). The life cycle is direct (Stahl, 1963). The female deposits embryonated eggs within the colon and on the perianal skin (Flynn, 1973). The eggs are infective within a few hours. The eggs are very light and will aerosolize, resulting in widespread environmental contamination. Embryonated eggs are infective towards other rodents and can survive for extended periods at room temperature (Baker, 1998). The host becomes infected by ingesting eggs directly from the perianal region of an infected animal or indirectly from contaminated materials, such as food and water or retroinfection (migration of hatched larvae from anus to colon). Adult worms occur in the cecum or anterior colon (Sasa et al., 1962; Stahl, 1963). The prepatent period of $S$. muris is 7 to 8 days (Lewis \& D'Silva, 1986).

Aspiculuris tetraptera (male $2-4 \mathrm{~mm}, 3-4 \mathrm{~mm}$ ) also has a direct life cycle, and mature worms are found in the cecum and colon (Habermann \& Williams, 1958; Sasa et al., 1962). Unlike Syphacia muris, which deposits eggs on the perianal skin, adult females $A$. tetraptera lay their eggs into the lumen of the colon, and the eggs are excreted in the faeces. The eggs take about 6 days to reach infectivity and infection of the host is caused by the ingestion of embryonated eggs. The prepatent period of $A$. tetraptera is about 23 days. (Taffs, 1976).

Although pinworm parasites of laboratory rodents are generally considered relatively non-pathogenic and infections are generally regarded as symptomless, no specific clinical signs appear even with serious infections. It has been suggested that infections affect weight gain, growth rate and general health (Wagner, 1988). Also pinworm infestation has been found to interfere with the occurrence of induced adjuvant arthritis (Pearson \& Taylor, 1975), and with intestinal electrolyte transport (Lubcke et al., 1992). Rodents with pinworm infection are not desirable 
experimental subjects, therefore it is important to maintain parasite-free laboratory rodent colonies.

The eradication of pinworm infections is extremely difficult, especially from large rodent breeding colonies. For their control, a colony should be started with parasite-free parents otherwise the administration of anthelmintics is required. Caesarian derivation or embryo transfer can be used to obtain parasite-free offspring in order to provide breeders for a new colony. Numerous anthelmintics, such as pyrvinium pamoate, fenbendazole, ivermectin, doramectin, moxidectin, piperazine, thiabendazole and mebendazole have been used to treat pinworm infection in laboratory rodent colonies (Blair et al., 1968; Taffs, 1976; Battles et al., 1987; Klement et al., 1996; Zenner, 1998; Huerkamp et al., 2000; Oge et al., 2000; Pritchett, 2002).

Ivermectim has become one of the most widely used drugs for the treatment of animal parasitic infections. Ivermectin is a member of the family of compounds produced by the soil microorganism Streptomyces avermitilis and known generically as avermectins (Campbell \& Benz, 1984). Ivermectin acts as an $\gamma$ - aminobutyric acid (GABA) antagonist in nematodes to cause paralysis (Frayha et al., 1997). Ivermectin is effective against two major phyla of animal parasites-the Nematoda (roundworms) and the Arthropoda (insects, ticks, and mites). Studies on its mode of action suggest that ivermectin is unlikely to be effective against species of the phylum Platyhelminthes (flukes and tapeworms); indeed, those platyhelminths that have been exposed to ivermectin have proved insusceptible (Campbell et al., 1983). It seems that cestodes and trematodes have nervous systems different from those of nematodes (Frayha et al., 1997).

Due to the fact that pinworm eggs have been found on equipment, in dust and in ventilation air-intake ducts, drug therapy should be backed by routine hygienic measures (Habermann \& Williams, 1958; Taffs, 1976).

The aim of this study was to investigate the effectiveness of orally administered ivermectin diluted in water as a treatment for adult pinworms and their larvae in laboratory rat colonies, and to evaluate the safety of the drug with respect to growth rate, behaviour and consumption of food and water.

\section{Materials and methods}

\section{Housing/animal care}

For our study, we used 148 outbred Wistar rats of either sex with natural pinworm infection - males with an average body weight of $240 \mathrm{~g}$, females with an average body weight of $160 \mathrm{~g}$. The rats came from the Institute of Physiology of the Academy of Sciences of the Czech Republic breeding facility and underwent an acclimatization period of 10 days. During the experiment, the rats were housed in a conventional animal room. The animals (in groups of $2-$ 3 per cage) were kept in type K5 clear styrofoam cages. Wood shavings were used for bedding. The room was maintained at $22 \pm 2^{\circ} \mathrm{C}$ and $55 \pm 5 \%$ relative humidity with natural lighting. The air was automatically ventilated $10-15$ times per hour. Pellet rodent food and tap water in drinking bottles were given ad libitum. Cages, bedding, steel wire tops and bottles were changed every fifth day.

\section{Drug doses}

In this study, ivermectin was delivered in drinking water. To determine the appropriate amount of the drug to add to the water, we did a pilot study to establish the average water consumption by rats. The daily water intake for 10 rats (five of each sex) was determined over a 5-day period. The mean daily water intake was $100 \mathrm{ml} / \mathrm{kg}$. Based on this water intake, rats were given $25 \mathrm{mg}$ of ivermectin (Ivomec; Merck) diluted in 1 liter of drinking water. Ivermectin is not readily soluble in water. In order to prevent its precipitation, the water bottles were vigorously shaken daily. Thus, during the treatment period, the mean ivermectin dose was $2.5 \mathrm{mg} / \mathrm{kg}$ per day.

\section{Cellophane - tape test}

A strip of transparent adhesive tape was pressed against the anus of the animal being investigated and then placed sticky side down on a clean slide and examined microscopically (Sasa et al., 1962).

\section{Necropsy}

After euthanasia, the rat's caecum and large intestinal contents were removed, collected into a Petri dish, diluted with saline and examined microscopically for adult pinworms and larvae.

\section{Study design}

All experiments were conducted in accordance with the Animal Protection Act. After the acclimatization period, a cellophane - tape test was performed on the entire population of experimental rats to confirm infection. Subsequently, the rats were randomly divided into four groups. The first one was the control (MC, $\mathrm{n}=14$ ) group and included male rats without treatment. The second control group ( $\mathrm{FC}, \mathrm{n}=14$ ) included female rats without treatment. The third group (MI, $\mathrm{n}=60$ ) included male rats to which ivermectin was administered. The fourth group (FI, $\mathrm{n}=60$ ) included female rats with ivermectin treatment, as well. All rats were weighed. Later, fourteen rats $(7$ males and 7 females) from the control group were euthanized $\left(\mathrm{CO}_{2}\right)$ and examined for adult pinworm and larvae. The experimental groups (MI and FI) received four courses of ivermectin which alternated with drinking water every 5 days. Ivermectin was administered for 5 days in drinking water; the ivermectin dose was $2.5 \mathrm{mg} / \mathrm{kg}$ of body weight per day. All rats were weighed every five days and their ova production was monitored by a cellophane - tape test. Every fifth day six males and six females from the experimental group were euthanized $\left(\mathrm{CO}_{2}\right)$, and their caecum and large intestinal contents were examined for adult pinworms and larvae. The rats' health condition, behaviour and consumption of food and water were monitored daily. 


\section{Statistics}

A statistical analysis was performed using a $t$ test for unpaired data. A $P$ value of less than 0.05 was considered statistically significant.

\section{Results and discussion}

Pinworm infection in the control group was detected by CTT and by determination of the parasite count during necropsy of rats. The results of the cellophane - tape test and the intensity infection in the control group are shown in Table 1. All rats in the control group had a positive result from the cellophane - tape test. The total parasite count was $836.71 \pm 81.10$ in males and $569.00 \pm 69.91$ in females. The males had higher intensity infection than females. cum and colon of the experimental animals after the first course of the ivermectine treatment (Table 2). Disparity between CTT and the parasite count can be explained by the adult parasites and larvae being eradicated in the large intestine and caecum, the eggs being glued around the anus and might have been the source of the infection.

Our study has shown that ivermectin is a highly effective anthelmintic. It is also relatively inexpensive, and has a wide margin of safety (Soll, 1989; Hickman et al., 2008) The results of various studies on the efficacy of ivermectin, however, have been variable, likely reflecting differences in doses, duration, and methods of administration. In our research, the four 5-day courses of ivermectin with daily doses of $2.5 \mathrm{mg} / \mathrm{kg}$ bodyweight eliminated pinworm infection from the laboratory rat colony. After the first five days of treatment, no adult pinworms and their larvae were

Table 1. Cellophane - tape test and parasite count in the control group

\begin{tabular}{cccccc}
\hline Group & \multirow{2}{*}{ CTT } & \multicolumn{2}{c}{ Parasite count } \\
& & S. m. female & S. m. male & S. m. larvae & Total \\
\hline MC & 100 & $296.00 \pm 42.54$ & $163.43 \pm 7.91$ & $377.29 \pm 39.07$ & $836.71 \pm 81.10$ \\
FC & 100 & $192.29 \pm 13.75$ & $100.57 \pm 13.06$ & $276.14 \pm 51.34$ & $569.00 \pm 69.91$ \\
\hline
\end{tabular}

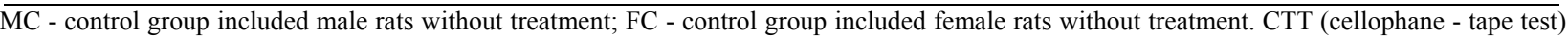
was determined in entire control group (14 males and 14 females) and expressed in \% of positive animals. Parasite count was determined in 7 males and 7 females of control group which were euthanized at the beginning of experiment.

All rats in the experimental group proved positive on the cellophane - tape test, as well (Table 2). During the ivermectin treatment, a number of eggs detected by the cellophane - test declined significantly during the first ten days. After the third course of ivermectin (the $25^{\text {th }}$ day of experiment), and until the end of the experiment all rats had negative CTT results.

As opposed to CTT, no parasites were detected in the cae- found in the large intestinal contents. After the second course of ivermectin, eggs were discovered in only one of the animals. In our case, this might have been an influenced result since the cellophane - tape test potentially served as a method of egg elimination from the perianal region. The control of Syphacia muris is difficult since a cross-infection may easily occur after the deposition of the eggs, which are infective for a few hours after laying. It is

Tab 2. Cellophane - tape test and parasite detection during ivermectin treatment in the experimental group

\begin{tabular}{|c|c|c|c|c|c|c|c|c|c|c|}
\hline \multicolumn{2}{|c|}{$\begin{array}{l}\text { Group / } \\
\text { Day of exam. }\end{array}$} & $\mathbf{0}$ & 5 & 10 & 15 & & 25 & 30 & 35 & $40-50$ \\
\hline & & \multicolumn{9}{|c|}{ Treatment } \\
\hline & & & $\mathbf{I v}$ & Water & Iv & Water & Iv & Water & Iv & Water \\
\hline \multirow{2}{*}{ CTT } & ME & 100 & 100 & 68 & 15 & 2 & 0 & 0 & 0 & 0 \\
\hline & $\mathbf{F E}$ & 100 & 100 & 62 & 7 & 0 & 0 & 0 & 0 & 0 \\
\hline \multirow{2}{*}{$\begin{array}{l}\text { Parasite } \\
\text { count }\end{array}$} & ME & - & 0 & 0 & 0 & 0 & 0 & 0 & 0 & 0 \\
\hline & $\mathbf{F E}$ & - & 0 & 0 & 0 & 0 & 0 & 0 & 0 & 0 \\
\hline
\end{tabular}

Iv - ivermectine treatment; ME - experimental group which included male rats with treatment; FE - experimental group which included female rats with treatment. CTT (cellophane - tape test) - was expressed in \% of positive findings 
a fact that ivermectin, although effective on adult pinworms and their larvae, has no effect on the eggs, which are very resistant and will survive ex vivo. Due to the eggs' resistance, the sterilants/disinfectants should be used to eliminate the eggs from the breeding room including the cages/equipment as illustrated by Dix et al., (2004). That is why the anthelmintic courses must be repeated. Repeating the treatments is necessary until eggs are extracted and eliminated via cage cleaning and animal hygiene, otherwise they develop into adult form in vivo and are eliminated by drug therapy. The effectiveness of the repeated treatments was confirmed after the fifteenth interval, during which, and after the last course of ivermectin, the rats were given only water. During this interval, the tests revealed no eggs in the perianal region or adult worms and larvae in the intestines.

Regular environmental decontamination, including changes of bedding, cages, bottles and wire tops must be a part of a pinworm eradication program. A. tetraptera eggs take about 6 days to reach infectivity once exposed to air and therefore regular cage cleaning and bedding removal are necessary to avoid the re-contamination of rats.

Despite the high dose of ivermectin administered (2.5 $\mathrm{mg} / \mathrm{kg}$ of body weight per day) and the length of treatment (20 days), the rats showed no signs of toxic reaction. Repeated application of ivermectin did not influence weight change in the rats (Chart 1). Although the rats in the experimental group experienced less weight gain, no significant changes between these groups were found. During our daily observations, the trouble disappeared after the longterm administration of $2.5 \mathrm{mg} / \mathrm{kg}$ ivermectin in water for the entire treatment period. All rats appeared to be in good health. Rats showed no change in behaviour, and their consumption of food and water was within normal ranges. The results of this study show that the oral administration of ivermectin through repeated short courses used in accordance with the present protocol is a safe and highly effective treatment for Syphacia muris and Aspiculuris tetraptera in laboratory rat colonies. The drug can be easily and safely administered in drinking water. This simple regime should control pinworm infection, a problem that can be endemic in laboratory colonies.

\section{Acknowledgements}

This study was supported by the Research Project of the Institute of Physiology, Academy of Sciences of the Czech Republic, v.v.i. No AV0Z50110509 and by the Research Project of the Faculty of Agrobiology, Food and Natural Resources, Czech University of Life Sciences in Prague, No. MSM 6046070901.

\section{References}

BAKER, D. (1998): Natural pathogens of laboratory mice, rats and rabbits and their effects on research. Clin. Microbiol. Rev., 11: $231-266$

Battles, A. H., Adams, S. W., Courtney, C. H.,
MLADINICH, C. R. T. (1987): Efficacy of ivermectin against natural infection of Syphacia muris in rats. Lab. Anim. Sci., 37: $791-792$

Blair, L. S., Thompson, P. E., VANDEnBelt, J. M. (1968): Effects of pyrvinium pamoate in the ration or drinking water of mice against pinworms Syphacia obvelata and Aspiculuris tetraptera. Lab. Anim. Care, 18: 314 - 327

CAmpbell, W. C., Fisher, M. H., Stapley, E. O., Albers - SCHÖNBERG, G., JACOB, T. A. (1983): Ivermectin: a potent new antiparasitic agent. Science, 221(4613): 823 - 828 CAMPBell, W. C., BenZ, G. W. (1984): Ivermectin: a review of efficacy and safety. J. Vet. Pharmacol. Ther., 7(1): $1-16$

DiX, J., Astill, J., Whelan, G. (2004): Assessment of methods of destruction of Syphacia muris eggs. Lab. Anim., 38: $11-16$

FLYNN, R. J. (1973): Parasites of laboratory animals. Iowa State University Press, pp. $239-242$

Frayha, G. J., Smyth, J. D., Gobert, J. G., Savel, J. (1997): The mechanisms of action of antiprotozoal and anthelmintic drugs in man. General pharmacology, 28(2): $273-299$

HabermanN, R. T., Williams, F. P. JR. (1958): The identification and control of helminths in laboratory animals. $J$. Natl. Cancer Inst., 20: 979 - 1009

Hickman, D., Swan, M., HartMan, G. P. (2008): A costeffective and efficacious method of pinworm treatment for large colonies of mice. Lab. Anim., 37(7): $308-312$

Huerkamp, M. J., Benjamin, K. A., Zitzow, L. A., Pullium, J. K., Lloyd, J. A., Thompson, W. D., WebB, S. K., LEHNER, N. D. (2000): Fenbendazole treatment without environmental decontamination eradicates Syphacia muris from all rats in a large, complex research institution. Contemp. Top. Lab. Anim. Sci., 39(3): 9-12.

Klement, P., Augustine, J. M., Delaney, K. H., Klement, G., WeITZ, J. I. (1996): An oral ivermectin regimen that eradicates pinworms (Syphacia spp.) in laboratory rats and mice. Lab. Anim. Sci., 46: $286-290$

Lewis, J. W., D'Silva, J. (1986): The life-cycle of Syphacia muris Yamaguti (Nematoda: Oxyuroidea) in the laboratory rat. J. Helminthol., 60: $39-46$

Lubcke, R., Hutcheson, F.A., BARBezAT, G.O. (1992): Impaired intestinal electrolyte transport in rats infested with the common parasite Syphacia muris. Dig. Dis. Sci., 37: $60-64$

OGE, H., AyAZ, E., IDE, T., DALGiÇ, S. (2000): The effect of doramectin, moxidectin and netobimin against natural infections of Syphacia muris in rats. Vet. Parasitol., 88: $299-303$

PeArson, D. J., TAYlor, G. (1975): The influence of the nematode Syphacia obvelata on adjuvant arthritis in the rat. Immunology, 29: 391 - 396

Pritchett, K. R., Johnston, N. A. (2002): A review of treatments for the eradication of pinworm infections from laboratory rodent colonies. Contemp. Top. Lab. Anim. Sci., 41: $36-46$

SASA, M., TANAKA, H., FUKUI, M., TAKATA, A. (1962): Internal parasites of laboratory animals. In: HARRIS, R. J. C. (Ed) 
The problems of laboratory animal disease, pp.195 - 214

SolL, M. D. (1989): Use of ivermectine in laboratory and exotic mammals and in birds, fish, and reptilies. In: CAMPBELL, W. C. (Ed) Ivermectin and abamectin. Springer - Verlag, pp. $260-286$

STAHL, W. (1961): Syphacia muris, the rat pinworm. Science, 133: $576-577$

STAHL, W. (1963): Studies on the life cycle of Syphacia muris, the rat pinworm. Keio J. Med., 12: $55-60$
TAFFS, L. F. (1976): Pinworm infections in laboratory rodents: a review. Lab. Anim., 10: 1 - 13

WAGNER, M. (1988): The effect of infection with the pinworm (Syphacia muris) on rat growth. Lab. Anim. Sci., 38: $476-478$

ZENNER, L. (1998): Effective eradication of pinworms (Syphacia muris, Syphacia obvelata and Aspiculuris tetraptera) from a rodent breeding colony by oral anthelmintic therapy. Lab. Anim., 32: 337 - 342 